\title{
Amniotic Fluid Embolism- A Catastrophic Syndrome in Pregnancy
}

\author{
Swati M. Patel ${ }^{1}$, Kunur Shah ${ }^{2}$, Mukesh Patel ${ }^{3}$ \\ ${ }^{1} \mathrm{MD}$, Department of Obstetrics and Gynaecology, Mayaan Maternity Hospital, Morbi, Gujarat, India. ${ }^{2}$ Assistant \\ Professor, Obstetrics and Gynaecology, IKDRC-ITS, Ahmedabad, Gujarat, India. ${ }^{3}$ MBBS, Mayaan Maternity Hospital, \\ Morbi, Gujarat, India.
}

\section{INTRODUCTION}

Amniotic Fluid Embolism is one of the most catastrophic complications of pregnancy. AFE more closely resembles an anaphylactic reaction to foetal debris and remains a diagnosis of exclusion. The clinical presentation of sudden profound dyspnoea respiratory failure followed by cardiovascular collapse and disseminated intravascular coagulopathy in a pregnant female highly gives the suspicion of AFE.(1) The maternal mortality rate is $61-86 \%$. We report a case of amniotic fluid embolism who survived because of timely life support treatment. Amniotic fluid embolism (AFE) is a catastrophic syndrome that occurs during pregnancy or in the immediate postpartum period. A 28-year-old 2 ${ }^{\text {nd }}$ para patient was referred to our hospital immediately after preterm delivery of an anencephaly baby with polyhydramnios with suspicion of AEF. Rapid maternal cardiopulmonary stabilization and circulation support had been given. Correction of coagulopathy \& correction of post-partum haemorrhage (PPH) by hydrostatic condom catheter as dynamic balloon tampon salvaged the patient.

\section{PRESENTATION OF CASE}

A 28 years old 2nd para female patient came to our hospital in August 2018 with history of sudden development of dyspnoea, hypotension, tachycardia and loss of consciousness immediately after delivery. She had 7 months of pregnancy, developed pain abdomen and delivered spontaneously vaginally in a local hospital within 8 hours of admission. She had polyhydramnios \& anencephaly male baby of $1.02 \mathrm{Kg}$. Suddenly after delivery she had breathlessness and tachycardia with hypotension. Patient was referred to our hospital after intubation. On the way, she self-extubated and convulsed.

Immediately intubation was done. Her heart rate was $160 / \mathrm{min}$ and blood pressure was not recordable. Her oxygen saturation $\left(\mathrm{SpO}_{2}\right)$ was $60 \%$ without oxygen therapy and bilateral crepitation in lungs was present. Crystalloid of 1 liter and colloid of 1.5 liters was given within 2 hours by intra venous route. Patient was kept on ventilator. Oxygen, IV fluids, antibiotics and blood (Packed Cell Volume -PCV) started. Her Haemoglobin was $10.3 \mathrm{gm} \%$, Platelet count was 2.1 lakhs/ cmm, Prothrombin time and APTT was more than $120 \mathrm{sec}$. Chest X ray suggested pulmonary oedema. She developed atonic post postpartum haemorrhage after 30 minutes.

Hydrostatic condom catheterization was done as uterine dynamic balloon tamponade. Condom was inflated with $500 \mathrm{ml}$ of warm saline in the uterus. 8 units of fresh frozen plasma (FFP), 2 units of platelet rich plasma (PRP), 4 units of packed cells and 4 litres of IV fluids were given within 12 hours. Condom catheter was removed from uterus after 16 hrs. Patient was extubated after 20 hours. Patient had slurred speech from which she recovered spontaneously in 1 week. Contrast enhanced computed tomography (CECT) of brain was advised by physician but not done due to non-affordability. She was discharged on 8th day. On follow up she is doing well.
Corresponding Author: Dr. Swati M. Patel, Mayaan Maternity Hospital, Savsar Plot Main Road, Near Old Bust Stand, Morbi-363641, Gujarat, India. E-mail: pateldrswati@yahoo.com

DOI: $10.14260 / j e m d s / 2019 / 663$

Financial or Other Competing Interests: None.

How to Cite This Article:

Patel SM, Shah K, Patel M. Amniotic fluid embolism- a catastrophic syndrome in pregnancy. J. Evolution Med. Dent. Sci. 2019;8(40):3050-3051, $10.14260 / \mathrm{jemds} / 2019 / 663$

Submission 14-02-2019,

Peer Review 18-09-2019,

Acceptance 25-09-2019,

Published 07-10-2019. 


\section{DISCUSSION}

The incidence of AFE is 1 in 8000 to 1 in 80000 deliveries with

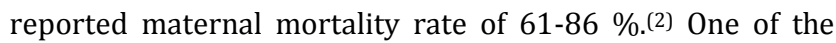
major factors that makes AFE so devastating is its total unpredictability. It is diagnosed largely by exclusion. The syndrome typically occurs during labour, soon after vaginal or caesarean delivery or during second trimester dilatation and evacuation procedures. Predisposing factors are - uterine over distension, intrauterine foetal death, trauma, polyhydramnios, large foetal size, high cervical laceration, premature separation of placenta and rupture of membranes. ${ }^{(3)}$

The cardinal criteria of amniotic fluid embolism are acute hypoxia diagnosed by dyspnoea Cyanosis and respiratory distress, followed by pulmonary oedema, left sided heart failure, haemorrhagic shock, confusion, convulsion, coma, severe coagulopathy and DIC. If patient survives, injury to brain, lungs and renal systems establish. It may last many weeks. Patient may die as a result of severe brain and lung injury, infection and multi organ failure. Immediate diagnosis and quick resuscitation can salvage the patient. There is no specific diagnostic laboratory tests for AFE but some tests may support the diagnosis. Arterial blood gas analysis determines adequacy of ventilation and degree of hypoxia. Zinc coproporphyrin, complements factor consumption monoclonal antibody THK-2 from peripheral blood samples are few markers.(4) For evaluation of DIC, D-dimer level, prothrombin fragment-2, platelet count, PT, PTT and fibrinogen level are helpful if abnormal. Chest radiography is a useful diagnostic test. The treatment is still not causative but supportive. Initial focus is on rapid maternal cardiopulmonary stabilization. Aggressive resuscitation to improve oxygenation, IV fluids, inotropic supplementation and correction of coagulopathy by blood products can save the patient.

AFE cannot be predicted or prevented. Timely reference to higher center after primary life supporting care like endotracheal intubation, aggressive early resuscitative measures by multidisciplinary approach by high index of clinical suspicion can decline the mortality. AFE usually occurs after delivery. However, when AFE occurs before or during delivery, early delivery of foetus increases the chance of better maternal outcome.(5)

\section{REFERENCES}

[1] Steiner PE, Lushbaugh CC. Landmark article, Oct 1941: maternal pulmonary embolism by amniotic fluid as a cause of obstetric shock and unexpected deaths in obstetrics JAMA 1986;255(16):2187-203.

[2] Clark SL, Hankins GD, Dubley DA, et al. Amniotic fluid embolism: analysis of the national registry. Am J Obstet Gyneclo 1995;172(4 Pt 1):1158-69.

[3] Dedhia JD, Mushambi MC. Amniotic fluid embolism. Continuing Education in Anaesthesia, Critical Care \& Pain 2007;7(5):152-6.

[4] Kaur K, Bhardwaj M, Kumar P, et al. Amniotic fluid embolism. J Anaesthesiol Clin Pharmacol 2016;32(2):153-9.

[5] Martin PS, Leaton MB. Emergency: amniotic fluid embolism. Am J Nurs 2001;101(3):43-4. 